ISSN 2179-345X

Licenciado sob uma Licença Creative Commons

\title{
Elementos da teoria keynesiana para uma reflexão sobre a intervenção jurídica estatal
}

\author{
Elements of the Keynesian theory for a \\ reflection on the state legal intervention
}

\begin{abstract}
Paulo Ricardo Opuszka ${ }^{[a]}$, Silvia Fráguas ${ }^{[b]}$
[a] Doutor em Direito pela Universidade Federal do Paraná (UFPR), professor do curso de Mestrado em Direito Empresarial e Cidadania do Centro Universitário Curitiba (UNICURITIBA), Curitiba, PR Brasil, e-mail: paulor.opuszka@gmail.com

${ }^{[b]}$ Mestre em Organizações e Desenvolvimento pelas Faculdades Associadas de Ensino (FAE), assessora jurídica do Grupo Positivo, Curitiba, PR - Brasil.
\end{abstract}

\section{Resumo}

O objetivo do presente artigo é articular as contribuições de John Maynard Keynes, no que tange à possibilidade de aproximação entre a teoria keynesiana e elementos que possam servir de diálogo entre o Direito e a Economia, a partir do problema da efetividade dos direitos ante a economia intervencionista, principal legado do autor, ainda em vigor nos tempos atuais. A compreensão das categorias de Keynes poderá contribuir para o levantamento de elementos que possibilitem uma intervenção social, ainda que 
no campo da reflexão teórica, capaz de aproximar as demandas sociais e a proteção dos direitos de comunidades, indivíduos, ou seja, brasileiros destinatários da referida política ou, ainda, as pistas de seu esgotamento. Compreende-se que no processo civilizatório ocidental as políticas sociais foram resultados ou subprodutos necessários das profundas transformações desencadeadas a partir do século XIX, sejam elas caracterizadas pelo fenômeno da industrialização e modernização das sociedades ou o advento do modo de produção capitalista e sua respectiva crise nos anos 30 do século XX. Se as políticas públicas são resultado da participação popular no processo de afirmação do Estado Democrático de Direito, a intervenção social sempre cabe na referida análise das bases do pensamento keynesiano.

Palavras-chave: Teoria keynesiana. Política social. Direito e Economia.

\section{Abstract}

The aim this paper is to articulate the contributions of John Maynard Keynes regarding the possibility of rapprochement between the Keynesian theory by finding elements that can serve as a dialogue between law and economics from the problem of realization of the rights before the interventionist economy, the main legacy of author, still in force nowadays. The understanding of the categories of Keynes may contribute to the lifting elements that enable a social intervention, even in the field of theoretical reflection, capable of bringing the social demands and protecting the rights of communities, individuals, of Brazilian recipients of policy or yet, the clues to his exhaustion. It is understood that the civilizing Western social policies were necessary results or byproducts of the profound transformations triggered by the nineteenth century, they are characterized by the phenomenon of the industrialization and modernization of companies and the advent of the capitalist mode of production and its accompanying crisis in 30 years of the twentieth century. If public policies are the result of participation in the process of affirmation of the democratic state social intervention always fit in this analysis of the foundations of Keynesian thought.

Keywords: Keynesian theory. Social policies. Law and Economics. 


\section{Introdução}

O objetivo do presente artigo é encontrar elementos que possam servir de diálogo entre o Direito e a Economia, no sentido de refletir o problema da efetividade dos direitos ante a economia intervencionista, principal legado do autor, ainda em vigor nos tempos atuais. É, também, discutir a proposta, os problemas e as soluções advindas da adoção das políticas sociais.

Quando se trata de discussão do modelo brasileiro, ainda que periférico, ou a intervenção capitalista apontada para garantia de direitos sociais, de forma bastante peculiar, pode-se refletir a respeito das possibilidades e dos limites das políticas públicas que ora se apresentam, em especial as políticas sociais, a fim de compreender qual fase do desenvolvimento social estamos vivendo.

A respeito do desenvolvimento social compreenda-se a referida categoria enquanto evolução no sentido de aumento no conjunto de direitos sociais que possam formar um colchão de direitos aos trabalhadores e beneficiários das políticas sociais.

A compreensão desse mecanismo poderá contribuir para o levantamento de elementos que possibilitem uma intervenção social, ainda que no campo da reflexão teórica, capaz de aproximar as demandas sociais e a proteção dos direitos de comunidades, indivíduos ou mesmo brasileiros, ou ainda as pistas de seu esgotamento.

No chamado processo civilizatório ocidental, as políticas sociais seriam resultados ou subprodutos necessários das profundas transformações desencadeadas a partir do século XIX, sejam elas caracterizadas pelo fenômeno da industrialização e modernização das sociedades ou o advento do modo de produção capitalista.

\section{Elementos do pensamento keynesiano}

A teoria keynesiana é bastante complexa e, aqui, será discutida tão somente a partir de seus elementos mais evidentes, nas categorias 
já analisadas em outros autores, quais sejam: trabalho, renda e papel do Estado (lembrando que mercadoria, juros, preço e moeda, em alguns momentos, terão que ser abordados, dada a correlação das referidas categorias na teoria em análise).

Keynes é um dos autores mais importantes do século XX. Sua teoria começa na defesa da necessidade imperiosa da esfera pública. O autor coloca o Estado dentro da Economia a partir da análise do mercado de trabalho.

O ambiente histórico e sócio-político é o dos anos 30, caracterizados pelas altas taxas de desemprego, não condizentes com o princípio máximo do liberalismo econômico que afirmava a - não regulamentação dos mercados constitui meio eficaz de alocação ótima de recursos garantindo equilíbrio automático da economia (OPUSZKA, 2010, p. 144).

A primeira afirmação que se opõe ao classicismo econômico, em especial, smithiano (em especial a autorregulação da mão invisível) é o fato de não existir equilíbrio autônomo. O contexto da grande depressão seguido da grande pobreza e do desemprego gerou a necessidade da teoria que desenvolveu.

Marx chama a atenção afirmando que o capitalismo é uma economia monetária e esse argumento será recuperado por Keynes. A Economia Capitalista encontrou a forma adequada centrada na tecnologia. Foi o momento da incorporação do aprimoramento técnico. Contudo, isso não pode estar submetido à racionalidade publica.

No centro do pensamento keynesiano estavam os elementos que foram utilizados pelos seus intérpretes de atender à necessidade de colocar o contrato de trabalho no plano de dimensão, em especial nos países subdesenvolvidos a partir da adequação dos gastos centrais de governo, setores públicos, ao lado dos gastos privados (SCHILLING, 1999, p. 127).

Os trabalhadores são subordinados às determinações dos capitalistas. O conjunto dos trabalhadores é a parcela da sociedade que 
depende da compreensão acerca do mercado de bens, sob o qual o mercado de trabalho está subordinado. Aparece dessa forma, em Keynes, a questão do desemprego involuntário.

Segundo Schilling (1999, p. 127), para Keynes,

acreditar que as leis do mercado poderiam por si só solucionar a crise era o mesmo que dar crédito às lorotas do Barão de Munchausen, aquele mitônamo que se salvou de um pântano puxando os próprios cabelos. Portanto, devia-se socorrer do intervencionismo estatal e da sua capacidade reguladora para minorar o desemprego.

Keynes enxergava o intervencionismo como uma alavanca de Arquimedes útil para retirar o mundo da depressão em que se encontrava. Para tanto, seriam necessários grandes gastos públicos, sustentados por uma rigorosa política tributária, para absorver aquela imensa massa de desempregados, desiludidos e temerosos que se encontravam aos milhares nas cidades ocidentais.

Retornando os trabalhadores ao emprego, ainda que percebendo baixos salários, fariam com que o resto da indústria, funcionando em capacidade ociosa, voltasse a produzir para o mercado, rompendo-se dessa forma o marasmo da estagnação que colocava tudo em perigo.

As pistas apresentadas por Keynes fizeram com que, por meio de ações concretas das diversas forças sociais e políticas, o Estado atuasse em face do principal defeito do capitalismo, ou seja, a incapacidade de oferecer o pleno emprego, e na arbitrária e desigual distribuição de renda. Desse modo, fez com que contemplasse os pobres como possíveis futuros integrantes de uma sociedade de consumo avançada.

O referido autor, embora apreciasse a elegância e a consistência do modelo econômico clássico - virtudes que os economistas contemporâneos, ainda hoje, almejam -, não se deteve em demolir esse modelo.

No modelo clássico, o investimento era governado pelos espíritos animais dos empreendedores, diante de um futuro imponderável. Assim também entendia Keynes. A mesma incerteza deu aos poupadores um motivo para cumular sua riqueza em ativos líquidos, como dinheiro, 
em vez de empregá-la em novos projetos capitais. Nessa preferência por liquidez, o ritmo do investimento vacilaria, sem uma força de mercado evidente para restaurá-lo. A demanda ficaria aquém da oferta, deixando trabalhadores dispostos na prateleira. Caberia aos governos reanimar a demanda, cortando as taxas de juro, se possível, por meio de obras públicas, se necessárias.

Sendo assim, de gestão de demanda sobreviveu à Depressão, tornando-se um dever de rotina dos governos. Eles eram ajudados por assessores econômicos que construíam modelos funcionais da Economia, quantificando as relações-chave.

\section{Relações (possíveis) entre Economia e Direito na intervenção keynesiana}

No plano das possíveis relações entre a Economia e o Direito, mais precisamente a Economia Política e o Direito - e mais precisamente ainda a Economia Política e o Direito Moderno na perspectiva do Estado Social e Democrático Brasileiro -, a intervenção possível será o colchão de direitos sociais alcançados até a presente fase civilizacional, em especial o caso brasileiro.

Sabe-se do limite da discussão alcançada em relação à desejada, no campo do conhecimento científico e acadêmico, especialmente no campo da Economia Política. Contudo, nossas contribuições se voltam para um pensar em conjunto, a partir de uma possibilidade de discutir ao mesmo tempo Direito e Economia Política, já que, no campo das Ciências Jurídicas, o Direito tangente à Economia é o Direito Econômico, ramo que não será objeto da presente proposta de tese.

Para tratar das questões jurídicas, aponta-se para três categorias especificas: 1) a regulação do trabalho ou a atual estrutura que garante a proteção dos direitos dos trabalhadores e o conjunto de leis que garantem o cumprimento efetivo da referida proteção, seja o aparelho estatal (Ministério do Trabalho, secretarias estaduais e municipais do trabalho, 
delegacias regionais do trabalho, tribunais do trabalho) ou as entidades sindicais (centrais, confederações, federações e sindicatos) que servem para manter e avançar nas conquistas da classe trabalhadora; 2) o Estado Social Democrático de Direito, proposto pela Constituição Federal de 1988 e que durou tão somente até a primeira proposta de emenda constitucional, em setembro de 1991 ; 3) as políticas sociais dos últimos governos, em especial os governos FHC I e II, bem como os governos Lula I e II.

A regulação do trabalho, fruto de árduas lutas que resultaram em grandes conquistas essenciais à dignidade dos trabalhadores, deve ser entendida no Brasil, modernamente, a partir dos anos 1990, após a abertura comercial promovida pelos governos Collor e Fernando Henrique Cardoso. É importante destacar que esses governos romperam com a política de substituição de importações, dando início ao processo de reestruturação produtiva dentro das empresas. Essa ruptura trouxe, também, uma mudança política no que se refere às relações de trabalho, qual seja, a flexibilização dos regimes de trabalho. A flexibilização dos regimes de trabalho, por sua vez, proporcionou uma inserção dos trabalhadores nos âmbitos social, político e, principalmente, econômico.

No entendimento de Márcio Túlio Viana, professor de Direito do Trabalho da Universidade Federal de Minas Gerais (UFMG), a flexibilização começou há muito mais tempo, em meados da década de 1960, com a criação do Fundo de Garantia por Tempo de Serviço (FGTS).

Nas últimas décadas, com as transformações trazidas pela globalização, como as fusões e aquisições de empresas, e um cenário global de desemprego, a tendência à flexibilização se confirmou, acompanhada da perda de efetividade do trabalhador no mercado (VIANA, 2007 apud DATT, 2007).

Segundo Siqueira Neto (1996), a flexibilização dos regimes de trabalho, e do próprio Direito do Trabalho, "consubstancia-se no conjunto de medidas destinadas a afrouxar, adaptar ou eliminar direitos trabalhistas de acordo com a realidade econômica e produtiva". Ele esclarece que: 
a flexibilização do direito do trabalho é também entendida como um instrumento de adaptação rápida do mercado de trabalho. Neste sentido é concebida como a parte integrante do processo maior de flexibilização do mercado de trabalho, consistente no conjunto de medidas destinadas a dotar o direito laboral de novos mecanismos capazes de compatibilizá-lo com as mutações decorrentes de fatores de ordem econômica, tecnológica ou de natureza diversa exigentes de pronto ajustamento (SIQUEIRA NETO, 1996, p. 82).

Cumpre aqui ressaltar que diante da flexibilização, anteriormente mencionada, o Direito do Trabalho não tem como interesse primordial, ao tutelar as relações de trabalho, ceifar garantias duramente conquistadas, como sugere Américo Plá Rodriguez ao afirmar que "o Direito do Trabalho nasceu e se desenvolveu para suprimir liberdades, restringir possibilidades, limitar as opções do empregador. A flexibilização nas relações de trabalho busca precisamente o contrário: recuperar liberdades e facilidades para o empregador". Certo é que as relações de trabalho, assim como qualquer relação social, determinam a vida cotidiana dos indivíduos e, como tal, precisam da regulamentação e da proteção, conferidas pelo Direito do Trabalho.

Voltando aos ensinamentos de Marcio Túlio Viana, em vez de se discutir mudanças no Direito do Trabalho e na própria Consolidação das Leis de Trabalho (CLT), entendendo-os como supressor das liberdades dos trabalhadores, necessário é combater a precarização nas relações de trabalho. Sustenta o autor que

a flexibilização da atual legislação trabalhista, da forma como é discutida, é ambígua e passa uma ideia positiva. [...] Na realidade, ela esconde uma rigidez nas regras. Dá a impressão de beneficiar o trabalhador, mas passa o poder para o lado mais forte, que é o do empregador (VIANA, 2007 apud DATT, 2007).

E segue, exemplificando:

chegou-se a ser discutido, anos atrás, alteração em uma norma que diz que o contrato do trabalhador não pode ser alterado por nenhuma 
das partes depois de assinado. A ideia era flexibilizar para que o patrão pudesse fazer alterações. Ele passa a ditar as regras e, num cenário de desemprego alto, o trabalhador fica à mercê (VIANA, 2007 apud DATT, 2007).

Nesse contexto todo, importante se faz entender o real significado do Estado Social e Democrático de Direito, que, ao contrário do que sustentam alguns juristas, não surge da mera superposição entre Estado de Direito, Estado Social e Democracia. Nesse sentido, é importante destacar as palavras de Jorge Reis Novais (2004), que explica com clareza o fator social do Estado do Direito:

\begin{abstract}
para que o "qualitativo" social aposto ao Estado não seja mero "afã retórico" não basta a intervenção organizada e sistemática do Estado na economia, a procura do bem-estar, a institucionalização dos grupos de interesses ou mesmo o reconhecimento jurídico e a consagração constitucional dos direitos sociais; é ainda imprescindível a manutenção ou o aprofundamento de um quadro político de via democrática que reconheça ao cidadão um estatuto de participante e não apenas, como diz Garcia-Pelayo, de mero recipiente da intervenção "social" do Estado (NOVAIS, 2004, p. 191).
\end{abstract}

Seguindo os ensinamentos do autor supracitado, resta evidente que com o surgimento dos direitos sociais, dentre os quais se destacam, também, os direitos do trabalho e dos trabalhadores, surge um novo modelo de Estado, positivamente atuante, para dar efetividade aos princípios e objetivos elencados no artigo $3^{\circ}$ da Constituição Federal de 1988. Isso importa dizer que o Estado Social incorpora o Estado de Direito e os princípios da democrática, tornando-se assim o que chamamos de Estado Social e Democrático de Direito. Vejamos as lições de Sundfeld:

em termos sintéticos, o Estado Social e Democrático de Direito é a soma e o entrelaçamento de: constitucionalismo, república, participação popular direta, separação de Poderes, legalidade, direitos (individuais, 
políticos e sociais), desenvolvimento e justiça social (SUNDFELD, 2002, p. 53).

Em linhas históricas, o Estado Democrático e Social de Direito passou por uma série de transformações. Dos direitos fundamentais, enxergados sob o prisma das liberdades, passamos ao dos direitos econômicos, sociais e culturais. As experiências mais significativas para a construção dos elementos centrais do Estado Social e Democrático de Direito são a Constituição de Weimar de 1919, a Constituição do México de 1917 e a Declaração dos Direitos do Povo e do Trabalhador, na Revolução Russa de 1917, e o New Deal nos EUA. O Estado Social, base do Estado Social e Democrático de Direito, nasce como contraponto ao liberalismo, mas não rompe com a ordem capitalista. Todavia, confere rumos mais igualitários à sociedade.

No Brasil, o Estado Social e Democrático de Direito tem seus primórdios na Era Vargas. É importante ressaltar que o Estado Brasileiro, marcado pelo período ditatorial, teve dois momentos democráticos longos: o primeiro compreendido entre 1945 e 1964; e o segundo, o atual, consagrado a partir da Constituição de 1988.

Falando em Constituição, a brasileira de 1988 possui amplo e denso programa social que visa, sim, à concretização da igualdade e da justiça social. Isso é confirmado pelo extenso rol de direitos sociais previstos na Carta Magna.

Os direitos fundamentais, constitucionalmente elencados, devem ser efetivamente garantidos para que todos os cidadãos apresentem-se como livres e iguais para influir no cenário político e democrático. No Estado Social e Democrático de Direito, destaca-se particularmente a importância dos direitos econômicos, sociais e culturais.

Conforme já mencionado, os direitos do trabalho, ou o direito ao trabalho, também compõem os direitos sociais, constitucionalmente garantidos. Sua sistemática é complexa. O valor social do trabalho é erigido constitucionalmente à condição de fundamento do Estado Social e Democrático de Direito. A valorização do trabalho funda, ainda, a ordem 
econômica e financeira, ao lado da livre-iniciativa, podendo ser vista, então, como um direito fundamental.

Em suma, o Estado Social e Democrático de Direito busca a efetividade dos princípios constitucionais, com observância aos direitos sociais e aos objetivos fundamentais da República.

Diante do cenário que colocamos nos itens anteriores, importante se faz apontar os principais traços e tendências das políticas sociais brasileiras, observando, especialmente, suas transformações no cenário de desenvolvimento econômico e político brasileiro, suas implicações no processo de acumulação e de hegemonia.

Há, nesse cenário, uma tendência à sobreposição do caráter focalizante ou residual das políticas sociais. Tendência que mantém relação direta com o padrão das políticas econômicas colocadas em nosso país.

Parte-se do conceito de desenvolvimento, em uma perspectiva crítica, e tomando como parâmetro o ideal de "desenvolvimento como liberdade" (SEN, 2000), segundo o qual são privações da liberdade a extrema pobreza, a fome coletiva, a ausência de direitos básicos, a carência de oportunidades, a opressão e a insegurança econômica, política e social. Assim, segundo Amartya Sen, a eliminação da privação de liberdades é constitutiva do desenvolvimento, configurando-se em seus próprios meios e, simultaneamente, seus próprios fins.

Juntamente com o desenvolvimento, importante se faz apontar as principais transformações das políticas sociais brasileiras no cenário de desenvolvimento econômico do país. É importante ressaltar, aqui, que nosso Estado tem uma habilidade histórica em reproduzir a hegemonia do capital, garantindo a legitimidade que sustenta o poder econômico nas mãos da elite.

Ao discutir essa questão e, em especial a focalização e a universalização, resta evidente a importância de pensarmos nas políticas sociais dentro de um contexto de projeto de país, afirmando, até mesmo, que não é papel exclusivo das políticas sociais a redução efetiva da pobreza e das demais privações de liberdade, apontadas por Amartya Sen em sua obra. 


\section{O pós-Segunda Guerra Mundial}

Durante quase três décadas após a Segunda Guerra Mundial, esses assessores econômicos pareceram saber o que estavam fazendo, conduzidos por um aparente equilíbrio entre a inflação e o desemprego. Contudo, sua credibilidade não sobreviveu aos choques do petróleo da década de 1970.

Segundo a Revista The Economist, o problema chega naquela década da seguinte forma: "esses condenaram as economias ocidentais à estagflação, uma combinação surpreendente de desemprego com inflação, que o consenso keynesiano compreendeu mal e deixou de evitar" ${ }^{1}$ (OPUSZKA, 2010, p. 165).

Entretanto, os aspectos referentes à crise do modelo do welfare state não serão objeto da presente análise.

Adroaldo Moura da Silva, na apresentação da Teoria Geral do Emprego, do Juro e da Moeda, o clássico de Keynes datado de 1936, sintetiza as principais categorias da teoria keynesiana que ora se apresentam, no intuito de servir como base de discussão para os capítulos posteriores, no que tange a relação e efeitos, no Estado Brasileiro da tese fundadora do welfare state nas Américas já que a Europa, de um modo geral (especial na Alemanha) antecipou algumas das conclusões cedendo à pressão das entidades sindicais e movimentos sociais (OPUSZKA, 2010, p. 146).

Segundo Silva (1985, p. 7),

a mensagem básica do livro está contida nas muitas vezes repetida proposição de que o sistema capitalista tem um caráter intrinsecamente instável. Ou seja, a operação da mão invisível, ao contrário do que ainda é sustentado por economistas de inclinação ortodoxa, não produz a harmonia apregoada entre o interesse egoístico dos agentes

1 THE ECONOMIST. Tradução livre de Luiz Roberto Mendes Gonçalves. Carta Capital, p. 66, 29 jul. 2009. 
econômicos e o bem-estar global. Em busca de seu ganho máximo, o comportamento individual e racional dos agentes econômicos - produtores, consumidores e assalariados - pode gerar crises a despeito do bom funcionamento das poderosas forças automáticas dos mercados livres. E essas crises advêm de insuficiências da demanda efetiva. Nisso se aproxima, dentre outros, de Marx; deste, no entanto, se afasta radicalmente quanto ao método de análise e quanto ao futuro do sistema capitalista.

De acordo com a tese keynesiana, para se estudar as denominadas flutuações nos níveis de produto e emprego, era preciso explicar as principais determinantes da demanda e da oferta agregadas. Dessa forma, poderia-se afirmar que os níveis de produção e emprego seriam determinados pelo que denominou igualdade entre oferta e demanda agregada, sem a garantia de que todos aqueles que queiram trabalhar possam efetivamente encontrar emprego.

Para Silva (1985, p. 191), Keynes centra sua discussão primordialmente nos determinantes da demanda agregada. Esta é então decomposta por bens de consumo e demanda por bens de investimento.

No texto clássico keynesiano, encontra-se que a denominada demanda por bens de consumo depende primordialmente da renda corrente dos agentes econômicos e, secundariamente, da taxa de juros.

Neste caso, a inovação do autor está na hipótese de que o nível de consumo cresça menos que proporcionalmente com relação à renda corrente. Ainda, que essa é uma relação estável. De outra sorte, a demanda por bens de investimento, dependeria da expectativa de lucro futuro dos empresários, por ele cristalizada no conceito de eficiência marginal do capital, e da taxa de juros (SILVA, 1985, p. 192).

Percebe-se que importa-nos a presente análise porque as suas consequências afetarão os conceitos de Keynes sobre renda, geração de emprego e, mais tarde, necessidade do Estado na circunstância em que o capitalismo se encontrava. 
Se, na hipótese analisada, a demanda por bens de consumo guardar relação estável com a renda, as flutuações da demanda agregada estariam associadas aos movimentos do nível de investimento que, se em crescimento, com expectativas otimistas de lucro futuro, os investimentos gerariam mais emprego, maior nível de produto e de renda e, portanto, maior nível de consumo e poupança (OPUSZKA, 2010, p. 167).

Por outro lado, se em depressão, expectativas pessimistas de lucro geram frustração de lucro da indústria de bens de capital, queda de emprego e de renda e, portanto, queda nos níveis de consumo e poupança. Nas flutuações do nível de investimento estaria, portanto, aquilo que foi denominado a chave da compreensão dos movimentos cíclicos do capitalismo.

É importante compreender que, em Keynes, investimento significa aquisição de equipamentos do setor produtor de bens de capital, ampliação da capacidade produtiva e, finalmente, expansão da produção corrente de bens de capital (SILVA, 1985, p. 193). Entretanto, não significa aquisição dos denominados bens físicos ou financeiros preexistentes e não reproduzíveis pelo sistema econômico, como é o exemplo da terra.

$\mathrm{Na}$ resposta para a pergunta - por que as decisões de investimento têm caráter instável? - residiria a grande contribuição de Keynes à teoria econômica.

Para Keynes, em qualquer decisão de investimento, o capitalista se vê obrigado a antever a evolução futura e, portanto, incerta do mercado para o produto específico a ser gerado pela nova instalação industrial; da mesma forma, a taxa de salário que ele espera pagar para o trabalhador que irá operar as novas instalações e, finalmente, o preço e a disponibilidade da matéria-prima a ser transformada com o auxílio do novo equipamento. Inquietações sobre o comportamento futuro de uma ou do conjunto destas variáveis terminam por constituir na fonte primária da instabilidade dos investimentos e, portanto, do nível de emprego. Em condições normais, o empresário estima a taxa de retorno de seu investimento (a eficiência marginal do capital) cotejando o lucro esperado, calculado a partir de sua visão sobre o comportamento das variáveis acima alinhadas, com o custo de aquisição dos 
equipamentos necessários à implantação de suas decisões de investimento. Se essa taxa de retorno é maior que a taxa para a obtenção de fundos ou de aplicação de recursos no mercado financeiro - ou seja, a taxa de juros - então ele se sente motivado à realização desse investimento (SILVA, 1985, p. 194).

\section{A instabilidade do capitalismo e as variáveis "lucro futuro e taxas de juros"}

Percebe-se que a instabilidade do sistema capitalista tanto pode advir de flutuações nas expectativas empresariais quanto do lucro futuro e do comportamento da taxa de juros. Para o autor, fica evidente que essas variáveis - as expectativas sobre o lucro futuro e a taxa de juros - não são determinadas arbitrariamente.

No lado das expectativas tem-se o que Keynes chama de animal spirits dos empresários, fundado na motivação básica do capitalismo: acumular, acumular e acumular. No entanto, aqui entram dois elementos fundamentais da teoria de Keynes para explicar como e por que a decisão de acumular pode ser postergada e assim engendrar crises. Primeiro, o fato elementar de que cada capitalista individualmente é prisioneiro de sua própria história. Ou seja, a decisão de expandir ou criar uma nova fábrica é também uma decisão de sair de um ativo de liquidez universal - a moeda ou o capital financeiro de mercado amplo para entrar num ativo específico - a exemplo de uma fábrica de automóveis - cuja liquidez (venda do automóvel) depende de condições específicas do mercado de automóveis. Ora, como as máquinas de produzir automóveis só podem produzir isso (e não podem ser transformadas a custo zero em máquinas de produzir leite em pó), segue-se que a decisão de investir é também uma decisão de assumir o risco de iliquidez de um mercado específico. Embora a sociedade seja inexoravelmente vítima de algum investimento sem sucesso, o capitalista individual poderia escapar da iliquidez a um custo financeiro, se houvesse mercado organizado para fábricas ou se o mercado de ações fosse um barômetro seguro sobre a valorização dos equipamentos existentes e fosse amplo 
o suficiente para absorver a venda das ações do empreendimento (SILVA, 1985, p. 196).

Ao afirmar que os mercados futuros ou de ações não são mais eficientes que o capitalista individual quanto a prever ocorrências futuras, Keynes (1985) dá ênfase à afirmação de que, em casos de certos tipos de empreendimentos (investimentos de grande intensidade de capital e longa maturação ou de produtos novos), o tipo de risco envolvido não é suscetível de medidas e, portanto, não dá azo à formação de mercados futuros. Isso representa a característica de animal spirits do empresário e, em consequência, a fonte eventual de instabilidade do capitalismo.

Em segundo lugar, Keynes elabora sobre o risco da iliquidez a partir da demanda de dinheiro. Este comandaria um, assim denominado, prêmio de liquidez sobre todas as demais mercadorias. Tal prêmio de liquidez determina, por seu turno, a taxa de juros².

Agora temos as duas peças básicas para melhor entender as flutuações do investimento, portanto, da demanda agregada: a escolha intemporal entre reter ativos de liquidez universal (moeda), de um lado, e empreender a criação de ativos de liquidez específica (fábrica de automóveis), de outro.

$\mathrm{Na}$ continuação da complexa exposição, o autor apresentará a denominada segundo lâmina da tesoura, ou seja, a denominada oferta agregada, compondo os dois lados de sua hipótese (OPUSZKA, 2010, p. 199).

Para Silva (1985, p. 197), a oferta agregada representaria o conjunto das motivações empresariais para ampliar ou contrair a produção e o emprego correntes e seu ponto de partida para a Teoria da Formação de Preços.

Assim sendo, continua a análise, da expectativa de quanto será absorvido pelo mercado e dado o processo de barganha de fixação da taxa de salário nominal, assim como o estoque de capital e a tecnologia portanto, a relação inversa entre nível de emprego e produtividade do

2 Keynes pensa em um sistema monetário estável e não sujeito a processos inflacionários crônicos ao fazer a referida afirmação. 
trabalho - o empresário fixa tentativamente o preço com o qual espera vender o volume planejado de produto (SILVA, 1985, p. 200).

Dessa forma:

Keynes demonstra que da presente equação, por resíduo, se realizada a venda esperada, ocorreria o lucro, que, portanto, define o volume planejado de vendas e, assim, a Oferta Agregada. Nesta fase da análise, os elementos críticos são: o processo de barganha entre capitalistas e assalariados, o qual fixa a taxa de salário nominal, onde Keynes se distancia da orientação ortodoxa que vê esta taxa como resultado das forças automáticas dos mercados livres; e a produtividade do trabalho, no que Keynes segue a ortodoxia (SILVA, 1985, p. 200).

Tais afirmações contribuem para a aproximação dos elementos centrais de sua tese que nos interessem quando se trata de análise de políticas públicas para desenvolvimento social.

Keynes questiona como esse sistema reage a um desequilíbrio qualquer. Para ele, esses desequilíbrios quase sempre ocorrem por meio da eficiência marginal do capital ou, como analisado anteriormente, potencial de lucro no investimento realizado.

Assim reflete o autor:

suponha-se que ocorra uma queda na eficiência marginal do capital, por conta de uma antecipação firme de escassez aguda de uma matéria prima básica, a exemplo do petróleo. Ora, num dado momento a estrutura de produção é um dado da história e é específica (fábricas para produzir automóveis, fábricas para produzir máquinas de automóveis, etc.), segue-se que a antevisão da escassez de petróleo representa um corte na demanda de máquinas para produzirem automóveis. Este corte, por sua vez, provoca queda de emprego e, portanto, de renda (salários não mais pagos pela indústria), a qual, por seu turno, provoca nova queda de demanda, desta vez no setor de bens de consumo (KEYNES, 1985, p. 152). 
Dessa forma, a queda inicial da demanda é ocasionada não por queda de renda corrente, mas sim por antecipação de um evento futuro.

Então, a resposta para o que fazer hoje com a renda, o lucro e, portanto, com a poupança gerada no momento imediatamente anterior à queda de investimento - ou ainda se não seria inevitável que essa renda se transformasse em demanda de outros bens, de consumo ou de investimento - estaria no rompimento de Keynes com os ensinamentos da Lei de Say.

Para Keynes, a preferência pela liquidez ou pela manutenção de ativos líquidos (moeda em circunstâncias de quedas de preços, como ocorreu na década de 1930, ou outros ativos com a expectativa de rentabilidade real positiva em situações inflacionárias) pode, em circunstâncias como a anunciada, constituir-se em uma alternativa vantajosa à demanda de novos equipamentos ou de bens de consumo.

Segundo a Lei de Say ${ }^{3}$, essa situação - com mercados livres - seria revertida pela queda da taxa de juros, de salários e de preços (OPUSZKA, 2010, p. 170-171).

Adroaldo Moura Silva lembra que Keynes então prevê que a queda da taxa de juros, ainda que importante para eventualmente recuperar o nível de investimentos, poderia não funcionar se a eficiência marginal do investimento caísse mais rapidamente que a taxa de juros. E essa queda poderia ser engendrada pela própria diminuição de salários e preços, a qual deprimiria mais ainda a eficiência marginal do capital.

3 A denominada "Lei de Say" refere-se ao economista francês J. B. Say. Sua Lei de Mercados afirmava que "uma vez que a oferta do produto era ou sustentava ou tornava efetiva uma quantidade correspondente de procura para outros produtos - visto que todos os produtos eram trocados uns pelos outros - a oferta total e a procura total juntas deviam, em todas as condições, ser iguais, e na forma mais complexa, levando em conta o papel dinheiro - isto é, seu papel "neutro" limitado como é geralmente concebido tanto no ramo "econômico geral" como no ramo monetário da teoria clássica primitiva - o argumento dizia que, uma vez que todos os gastos na produção ou para produção entravam nas rendas e formavam as rendas das pessoas como contribuintes de trabalho e outros requisitos de produção, a renda total da população era necessariamente sempre suficiente para comprar a produção de todos os produtos a um nível de preços que cobria totalmente as despesas de produção". TAYLOR, O. História das idéias sociais. Tradução de History of Economic Thought. Rio de Janeiro: Fundo de Cultura, 1965.

Rev. Direito Econ. Socioambiental, Curitiba, v. 3, n. 2, p. 465-489, jul./dez. 2012 
Este processo terminaria também por se constituir num desastre social, por promover ociosidade do equipamento instalado e desemprego. Isso representa uma severa crítica a um dos mitos sagrados da moral burguesa: não funciona, portanto, a convergência entre o interesse individual (no caso a preferência pela liquidez) e o coletivo (o máximo emprego possível da força de trabalho). E este conflito de interesses é produto do funcionamento dos mecanismos automáticos dos mercados livres (OPUSZKA, 2010, p. 171).

\section{A legitimação da ação do Estado como elemento do funcionamento do sistema econômico}

Para escapar da denominada armadilha da recessão e evitar a acumulação improdutiva gerando demanda efetiva, surge o conteúdo que mais nos interessa: a legitimação da ação do Estado como elemento integrante e indispensável ao bom funcionamento do sistema econômico capitalista. Na verdade a proposta de Keynes era de curto prazo. A luta política e a ameaça do socialismo foi o ponto que, de fato, efetivou a denominada nova política pública.

Para Keynes, ao Estado caberia, portanto, eliminar a insuficiência de demanda efetiva em momentos de recessão e desemprego:

fazendo déficit orçamentário e emitindo títulos para extrair a renda não gasta do setor privado e com ela garantir que as máquinas ociosas voltem a operar. E aqui mais dois mitos da Economia Clássica caem. A poupança era encarada como um dos pilares da moral burguesa. A causa da depressão é a poupança excessiva frente a expectativa de lucro futuro num momento de elevada preferência pela liquidez. Crise, portanto, representa carência de investimento e ociosidade de máquinas e homens, e não, como apregoado, carência de poupança. Destrói também o mito de que a operação do Estado se deve pautar por grande austeridade financeira, não se gastando mais do que a coleta em tributos. Mostra, assim, que em circunstâncias de desemprego o déficit fiscal é uma peça importante para o bom funcionamento do sistema econômico (SILVA, 1985, p. 201). 
A respeito do déficit, é necessário fixar um ponto importante. Um déficit pode ocorrer tanto por aumento de despesas quanto por queda de tributos. Em uma situação de depressão, no entanto, só o aumento de despesas garante o aumento de demanda efetiva; queda de tributação pode gerar, simplesmente, maior demanda de ativos líquidos.

A análise de Keynes é importante porque oferece todas as pistas teóricas para que os atores internalizassem a ação do Estado como regulador de ciclos econômicos.

É inevitável apontar a incorporação da política keynesiana, de forma permanente, quando considerado o olhar de Celso Furtado sobre essa interpretação, que produziu suas análises econômicas dentro do quadro keynesiano, anteriormente apresentado, utilizando-o para elaborar uma séria crítica ao capitalismo.

Embora possa parecer bizantina, a discussão reveste-se de extrema importância, em razão da influência cada vez mais vasta da Economia sobre nossas vidas. Ao contrário de muitos pensadores da atualidade, Celso Furtado a encarava como uma ciência - social e histórica. Ele a via, portanto, com olhar ideológico muito definido, dentro de um determinado contexto histórico, servia-se dela para intervir na realidade social. Sua maior obra, Formação econômica do Brasil, é considerada um clássico nas Ciências Econômicas. Publicada em janeiro de 1959, analisa a Economia brasileira em um contexto histórico em movimento, em que não se chega nunca a um fim. E é ele mesmo quem o diz, em sua entrevista: "nunca procurei chegar a um final no meu livro. Trata-se de uma obra inacabada, própria da economia, própria da história".

Nas ultimas décadas, em um mundo totalmente globalizado e interdependente, a Economia desenvolveu estruturas tão poderosas de intervenção na vida social que teria subjugado as demais ciências, moldando o mundo às suas concepções. Perdeu, então, seu caráter histórico transformador, realizando-se como instrumento perpetuador e maximizador do mundo articulado pela burguesia liberal contemporânea.

Nesse quadro, o homem contemporâneo está totalmente dominado pelos preceitos econômicos. Não pode viver sem levar em conta os 
caminhos traçados pelos economistas. Uma oscilação em bolsa de valores, do outro lado do mundo, pode alterar completamente a sua vida.

O mercado rege sua postura. Desde o momento em que acorda até a hora de se deitar, está-se submetido aos seus desígnios, abrindo mão de uma existência criativa em troca de uma vida-não-vivida, de um mundo artificial.

Mais do que isso: mesmo os seus sonhos serão moldados pelas estruturas econômicas. Todo o processo de vida social e individual é submetido à banalidade terrível do dinheiro e do seu desenvolvimento tautológico. Em sua superfície, está a famosa economia de mercado. Exigem-se profissionais altamente qualificados para decifrar e operar suas estruturas, em um processo técnico anti-histórico, repetitivo, que não busca chegar a lugar algum. Tais profissionais, súditos de uma máquina infernal, não teriam, pois, qualquer sentimento ou paixão, operando apenas para a reprodução do capital na sua escala mais transcendental: de forma mecânica e definida globalmente.

\section{Considerações finais: um adendo especial sobre a influência de Keynes na interpretação do Brasil - reflexões em Celso Furtado}

Celso Furtado foi influenciado pela herança keynesiana, segundo a qual o Estado era um ator decisivo na garantia do bem-estar social. Após passar a Guerra na Europa e presenciar a reconstrução do continente ao fim do conflito, ele retorna ao Brasil com grandes ideias de mudança da sociedade, tendo o Estado como força motriz e o planejamento como meio de ação. Agrega-se, então, à equipe da Cepal, dirigida por Raúl Prebisch. Esse economista argentino, conhecido articulador do pensamento das economias periféricas, havia contextualizado a Teoria da Relação entre Centro e Periferia. Prebisch ([19-?] apud FURTADO, 2012) dizia: "o mundo está composto por países centrais, que [...] produzem manufaturas e controlam as inovações tecnológicas, que está consubstanciada com a manufatura; e os países periféricos, que exportam matérias-primas e consomem os bens manufaturados desses países". Ele propunha superar 
essa dicotomia centro-periferia. Orientado por tal objetivo, criou o pensamento cepalino, que teve em Celso um dos mais brilhantes formuladores.

Furtado defendia a industrialização do Brasil, como forma de conter o fluxo de riquezas que se esvaíam para o exterior, mantendo-nos sempre na posição de subalternos. Conseguiu influenciar o segundo governo de Vargas e, mais adiante, os governos JK e João Goulart. Seu entusiasmo, e a clareza com que defendia suas ideias, contagiaram esses presidentes, que se esforçavam por tê-lo como elemento auxiliar em seus governos.

As ideias de Celso e de muitos de seus companheiros e seguidores foram esmagadas pela grande tragédia do golpe militar de 1964. Este é, ao lado da Revolução de 1930, um dos mais importantes episódios da nossa história recente. Em 1930, libertaram-se as forças internas contidas pelo sistema agrário anacrônico, lançando-se o país na modernidade. Em 1964, essas mesmas forças antes libertadas foram contidas e esmagadas, por acalentarem a utopia de conduzir o país a um processo desenvolvimentista independente, permitindo-lhe emergir, na terceira revolução industrial, em pé de igualdade com o chamado "primeiro mundo".

Ademais, é inevitável apontar, conforme os ensinamentos de Keynes, que o homem se individualiza pelo trabalho na modernidade, vendendo sua força de trabalho para empresas, com a mediação do Estado, que regulamenta as normas gerais de trabalho por meio da Consolidação das Leis Trabalhistas. Por sua vez, o Estado é o espaço da participação popular na mediação da democracia, que se faz necessária para a edição de políticas públicas, nada mais devendo ser do que a síntese da vontade popular.

A política pública é o que faz a lei e a sua real efetivação. Assim, em Keynes, que prevê a política a curto prazo, podemos observar como essas políticas públicas são anticíclicas, ou seja, surgem a partir do financiamento público da economia capitalista. Por outro lado, no Brasil, temos que o financiamento da produção pelo Banco Nacional do Desenvolvimento (BNDES) é uma política de longo prazo.

É evidente, assim, a incorporação da política keynesiana de forma permanente, sob o olhar e a interpretação de Furtado, quando se aponta que o financiamento do BNDES pode ser uma alavanca para as 
políticas públicas, em especial as ambientais, que interferem diretamente no funcionamento da Economia no Estado brasileiro.

Eis, portanto, os pilares teóricos que informaram a política econômica a partir dos fins da década dos 1930, a qual foi decisiva para a saída da Depressão e muito ajudou o crescimento sem precedentes do capitalismo industrial do pós-Guerra.

A atividade econômica do Estado na geração de demanda efetiva é definitivamente incorporada à prática econômica do sistema capitalista para revigorá-lo. Na maior nação capitalista do mundo, os Estados Unidos da América do Norte, as compras de bens e serviços do Governo Federal passam de 2,5\%, em 1929, para 10\% do Produto Nacional Bruto em 1939.

Fruto das análises das seções anteriores, é perceptível que as instituições do Estado de Bem-Estar punham limites ao capitalismo segundo a teoria keynesiana. Entretanto, as teses de que as políticas de bem-estar serviriam como adequação do modelo capitalista sensível a um poder - denominado por autores como István Mesáros - mecanismo de sociometabolismo do capital (MESZÁROS, 2002), adequaram, no seu atual estágio, a necessidade de reprodução do trabalho visando a novas possibilidades de acumulação.

Do choque entre as nuanças das referidas correntes, em meio a discussões sobre a verdadeira origem do Estado de Bem-Estar Social, surge uma necessária adequação do modelo ao capitalismo periférico. Este se dá, especialmente no Brasil, ao fim dos anos 1920, em especial a partir do capitalismo instalado pelo governo do Presidente Vargas, denominado capitalismo de Estado, já que foi o fundo público financiador do projeto de desenvolvimento inicial do modelo brasileiro.

\section{Referências}

DATT, F. Flexibilizar: sim ou não? Disponível em: <http://noticias.universia. com.br/destaque/noticia/2007/05/04/424359/lexibilizar-sim-ou-no.html〉. Acesso em: 25 ago. 2011. 
FURTADO, C. Economia para a liberdade. Disponível em: <http://www. outraspalavras.net/2012/03/22/celsofurtado-economia-para-a-liberdade/>. Acesso em: 29 dez. 2012.

KEYNES, J. M. Teoria geral do emprego, do juro e da moeda. Tradução Mario R. da Cruz. 2. ed. São Paulo: Nova Cultural, 1985.

MESZÁROS, I. Para além do capital. São Paulo: Boitempo, 2002.

NOVAIS, J. R. Princípios constitucionais estruturantes da república portuguesa. Coimbra: Coimbra, 2004.

OPUSZKA, P. R. Cooperativismo popular: os limites da organização coletiva do trabalho a partir da experiência da pesca artesanal do extremo sul do Brasil. 2010. 282 f. Tese (Doutorado em Direito) - Universidade Federal do Paraná, Curitiba, 2010.

SEN, A. Desenvolvimento como liberdade. São Paulo: Companhia das Letras, 2000.

SCHILLING, V. Keynes versus Hayek. Porto Alegre: AGE, 1999.

SILVA, A. M. Apresentação da teoria geral do emprego, do juro e da moeda: inflação e deflação. 2. ed. São Paulo: Nova Cultural, 1985.

SIQUEIRA NETO, J. F. Flexibilização, desregulamentação e direito do trabalho no Brasil. In: OLIVEIRA, C. A. B. (Org.). Crise e trabalho no Brasil: modernidade ou volta ao passado? 2. ed. São Paulo: Scritta, 1996. p. 78-94.

SUNDFELD, C. A. Fundamentos de direito público. 3. ed. São Paulo: Malheiros, 2002.

TAYLOR, O. História das idéias sociais. Tradução de History of Economic Thought. Rio de Janeiro: Fundo de Cultura, 1965. 
THE ECONOMIST. Tradução livre de Luiz Roberto Mendes Gonçalves. Carta Capital, p. 66, 29 jul. 2009.

Recebido: 24/02/2012

Received: 02/24/2012

Aprovado: 15/07/2012

Approved: 07/15/2012 